\title{
FORMAÇÃO GERONTOLÓGICA: \\ narração crítica em torno do aprendizado de alunos em casas de longa permanência
}

\author{
Agostinho Both* \\ Mara Regina Viecili Azambuja**
}

\section{Resumo}

O texto apresenta-se em narrativas críticas a partir dos relatórios de uma prática de aprendizado em casas asilares, na Disciplina de Psicologia do Desenvolvimento III, produzidas pelas alunas do Curso de Psicologia da Universidade de Passo Fundo, no ano de 2000. A idéia central reside na crítica em torno do aprendizado acadêmico, o qual se realiza sem a preocupação de desenvolver o sentido das responsabilidades éticas face aos conhecimentos gerontológicos. O propósito das narrativas pretende evidenciar a importância de um aprendizado que aproxima o senso científico ao desenvolvimento ético dos alunos. A intenção deste texto reside no fato de se aperfeiçoar o aprendizado acadêmico, o qual possui, como regra fundamental, a racionalidade atenta aos problemas, enquanto metodologicamente correta. A análise qualitativa do relato das alunas, pretendeu desenvolver um perfil universitário vinculado à moralidade $\mathrm{e}$, como conseqüência, à busca de costumes sociais mais justos. Em conclusão, pode-se dizer que as alunas revelam perplexidade e impotência diante de um quadro social de muito sofrimento e de pouco aprendizado prático no espaço acadêmico. Evidenciouse a necessidade de intervenções sociais mais convenientes junto às casas asilares.

Palavras-chave: Formação. Ética e Velhice.

\section{Introdução}

A pretensão do iluminismo foi de tornar livre o ser humano, ampliando a racionalidade a ponto de não apenas conformar a vontade e a compreensão ao domínio da natureza em geral, mas de dominá-la superando-a, deixando

* Professor da Universidade de Passo Fundo (UPF). Doutor em Educação pela Universidade Federal do Rio Grande do Sul (UFRGS).E-mail: agoboth@terra.com.br

** Mestre em Educação pela UPF. E-mailmva@ginet.com.br 
para trás as antigas representações da fé e da caridade. Nesse sentido, a universidade, obediente a essa inclinação ideológica, perdeu muito do sentido da cidadania e da solidariedade, encontrando suficiente justificativa apenas na ciência para o fazer acadêmico e a formação de seus alunos.

O presente estudo busca discutir, através de um trabalho de campo, as formas acadêmicas perpassadas pelos princípios da racionalidade instrumental. O estudo inicial constitui-se como uma demonstração prática da realidade do desenvolvimento humano em situação de idosos residentes em casas de longa permanência. A proposta foi realizada aos alunos do quarto nível do Curso de Psicologia da Universidade de Passo Fundo, como estudo prático na disciplina de Psicologia do Desenvolvimento III. Apresenta-se como autocrítica das formas tradicionais de o aluno estudar a realidade social e, neste caso, uma das precárias realidades sociais: o atendimento dos idosos em casas de longa permanência.

A intenção deste estudo também pretende oferecer subsídios ao aprendizado acadêmico diante da necessidade de intervenções sociais associando os esforços da compreensão científica às expectativas morais. Vincula-se também ao impacto que a perda da autonomia e outros sofrimentos em casas de longa permanência causa nos jovens, avaliando igualmente como os alunos arranjam suas interpretações.

A autocrítica que perpassa o texto tem por base a visão habermasiana, pois entende-se que as ciências têm abandonado excessivamente as questões éticas sobre os temas que são abordados, principalmente nas questões do desenvolvimento social. O discurso, mediatizado pelo mundo-da-vida, ao contrário, busca ultrapassar o discurso da racionalidade sem a consideração de finalidades morais, uma vez que, conforme a teoria da ação comunicativa ${ }^{1}$, a ciência e a política não podem esquecer as demandas éticas.

Acompanhando esse raciocínio está a universidade ao inibir, na formação acadêmica, os interesses maiores de uma racionalidade capaz de avaliar, de forma abrangente e responsável, os objetos sociais que estuda.

\footnotetext{
1 No seu livro: Teoria de la Acción Comunicativa (Madrid: Taurus, 1992), Habermas escreve: “[ ... ] a burocratização se apodera dos processos espontâneos da formação de opinião e da vontade coletivas e esvazia seus conteúdos; amplia de um lado o espaço para a mobilização planificada da lealdade generalizada da população mas, de outra parte, facilita a desconexão das decisões políticas a respeito dos aportes de legitimação procedentes dos contextos concretos do mundo da vida formadores da identidade." (p. 461). Esta afirmação se aplica de modo especial ao pensamento universitário que protagoniza o projeto iluminista de forma radical.
} 
Fica, então, à mercê de explicações mais ou menos distantes dos compromissos éticos.

É isto que se pretende: associar os esforços da compreensão científica às expectativas morais, pelas quais os alunos possam desenvolver um pensamento crítico e cuja performance venha a contribuir, efetivamente, para a melhoria das condições de vida. Na presente narrativa olha-se criticamente a experiência das alunas de psicologia, enquanto é estudada a realidade das casas de longa permanência.

\section{Vendo o Problema de Perto}

$\mathrm{O}$ interesse deste trabalho vincula-se ao impacto que a perda da autonomia dos idosos e outros sofrimentos em casas de longa permanência causa aos jovens e às formas do ensino levadas a efeito junto a eles. Pretendiase, inicialmente, apenas aproximar os idosos dos jovens para que estes tivessem uma melhor compreensão da realidade asilar e de suas implicações biopsicossociais. Após a leitura dos relatórios ficou pendente uma questão: O aprendizado realizado foi suficiente para a formação dos alunos? Isso foi suscitado pela leitura dos relatórios, os quais evidenciavam surpresas, dores, impotência e, sobretudo, um impacto profundo diante da natureza humana e diante da própria sociedade que revelava sua face perversa. A autocrítica sobre o encaminhamento dado oferece-nos o principal interesse deste artigo, porquanto quer se constituir em análise do ensino visto apenas na ótica de um conhecimento e distanciado da responsabilidade ética.

Podemos dizer, de forma breve, que o objeto de nosso estudo é buscar compreender melhor como as alunas arranjam suas interpretações e como estas são oferecidas na academia, ou seja, como disciplinamos o entendimento sobre o abandono e os parcos recursos do aprendizado para resolver o impacto que essa defrontação aguda causa nos mais jovens.

Para poder minimizar os efeitos ameaçadores das realidades sociais que se impõem às crianças e jovens, existem representações sociais que buscam explicar aos mais jovens e às crianças o que está acontecendo. Muitas vezes sofremos os limites, porém não os estranhamos a ponto de os problematizarmos e encaminharmos alternativas significativas para sua solução. O que acontece, em geral, é que explicamos os fatos constrangedores e, de modo especial, as universidades buscam sistematizar o conhecimento em torno de alguns constrangimentos sociais, entendendo que, pelo processo do 
conhecimento, os problemas de alguma forma estão sendo controlados; os males estariam, então, exorcizados pela ciência. Ainda permanece vigorosa a idéia cartesiana de que as aproximações cognitivas dão conta daquilo que nos desagrada e que, dessa maneira, afastamos nossos problemas. A explicação torna-se mais ou menos burocrática, mas não chegamos a complicar e nos envolvermos nos acontecimentos. Existe uma espécie de "higiene acadêmica" que entendemos suficiente para dar conta dos sofrimentos sociais.

O fenômeno do abandono a que, cada vez mais, os mais velhos são submetidos perturba superficialmente as instituições de ensino superior, quando as perturba, isto é, nem ao menos existem os cuidados acadêmicos de ensino, pesquisa e extensão suficientemente delineados em torno da velhice tardia e de suas implicações sociais. Então, os eventos em torno do envelhecimento e da velhice não provocam nos alunos atenção e compreensão necessárias. Por outro lado, não existem efetivas políticas sociais que possam dar conta dessa velhice tardia com seus vínculos familiares fragilizados, sem autonomia e independência. O estudo prático sobre o abandono e o sofrimento de idosos, nas casas de longa permanência de Passo Fundo, realizado com os alunos da disciplina de Psicologia do Desenvolvimento III, é incipiente e, por certo, não está inserido ainda dentro de um projeto institucional mais global, contudo revela o interesse de uma universidade dar início a uma caminhada em face do entendimento da longevidade transformada.

A disciplina foi ministrada por um educador, com auxílio de uma psicóloga e de uma aluna bolsista. Não havia compreensão global dos impactos sociais e afetivos e de suas formas de reconstrução no início das atividades práticas da disciplina, nem estava em questão o estudo de intervenções necessárias para a superação ou minimização da experiência. Não havia a preocupação de se conduzir de forma mais objetiva e eficaz o aprendizado sobre a gestão ética dos mais velhos em casas asilares. A pretensão era, então, oferecer uma situação mais ousada de aprendizado nas questões referentes à velhice e suas implicações nos casos de perdas de vínculos e precipitação de fragilidades. Somente após os relatórios, percebeu-se o quanto a realidade havia sido tratada de forma burocrática, avaliando-se tão somente o universo explicativo do fenômeno em questão. 


\section{Impressões das Alunas sobre a Velhice e sobre as Casas de Longa Permanência}

As pessoas, quando envelhecem, limitadas pelas condições biopsicossociais, diminuem, proporcionalmente, as suas dificuldades e as suas perspectivas na vida. Quando não mediadas por instituições onde possam obter comunicação em torno de objetivos, torna-se natural o costume de contar seus dias a partir daqueles vividos, não a partir dos que virão. Elas não são mais orientadas para o futuro. Embora o envelhecer seja um processo natural na evolução do ser humano, assim constituído, intimida-nos sobretudo pela visão que nos foi dada das casas, ficamos perplexas em perceber o que foi visto e ficamos "devendo" melhor sorte aos mais velhos, com suas existências reduzidas a ponto de nos causar vergonha.

Entendemos que a precisão do juízo que formamos sobre a velhice depende não somente da veracidade e da bagagem de informações obtidas, mas, especialmente, da interpretação que damos a elas, que, por sua vez, depende da interpretação dada pela própria cultura em que estamos profundamente mergulhados. Nossa sociedade desenvolveu pouca tolerância e compreensão em relação aos "diferentes", aos “desviantes”, ou às chamadas "minorias". Esse conjunto quase infindável de tipos de pessoas pode incluir categorias sociais como judeu, negro, mulher, homossexual, pobre e idoso. As influências culturais na formação de estereótipos são camufladas através de explicações de caráter naturalista ou cultural. Assim, é comum a invocação de argumentos de "custo-benefício social", pelo qual conta a capacidade de produção mais que a vida.

Isolam-se, então, completamente os seres "deixando-os morrer", ou se suicidar. O certo é que: sofrem com o declínio do corpo e com as restrições sociais, mas, de alguma forma, desenvolvem formas esquivas para a construção de sua identidade existencial. Vimos essa velhice reclusa e confessamos nossa tristeza e perplexidade.

Em relação à diminuição da capacidade adaptativa do idoso às variações sociais, observamos um aumento de sua dependência do ambiente familiar, caracterizando-se a família como um local de estabilidade e de proteção. Todavia, atualmente, esse espaço social é nuclear, nele convivendo pais e filhos, com pouco lugar para a figura dos avós e colaterais. É claro que, diante dessas condições, a assistência ao idoso pode se tornar extremamente difícil e complexa, podendo chegar a uma institucionalização 
do idoso, em lares substitutos. Entendemos que, se esse fato fosse inevitável, seria indispensável a presença de uma equipe multidisciplinar. E esta, pela exigência da dignidade humana, buscaria reproduzir um ambiente familiar dentro da instituição, tendo o idoso seus objetos pessoais, peças de decorações e, sobretudo, a liberdade para horários de visitas aos residentes. Porém, é possível haver medidas intermediárias que permitam ao paciente idoso permanecer vinculado à família, como centros de convivência, centrodias, hospitais-dias, e outros recursos a serem criados. Entendemos que, se houvesse uma rede social de apoio às famílias, muitas delas poderiam atender, até de boa vontade, seus idosos dependentes em suas residências. Mas, em razão de fragilidades de toda ordem, principalmente pela pobreza, alguns idosos ficam abrigados em casas que não foram suas.

Diante da impossibilidade de o idoso poder dispor de recursos sociais mais íntimos, isso poderá levá-lo, então, à situação de abandono. Uma série de complicações derivadas de insuficiência material e psicológica do grupo familiar em relação ao idoso poderá provocar a situação de sofrimento potencial ou efetivo, físico ou psíquico, que, independentemente de suas causas, foram por nós agrupadas sob o título de "síndrome de insuficiência familiar". Isso nos leva a crer que muito mais se deve pensar e fazer que apenas ficar satisfeitos por entendermos o que está acontecendo, sem, porém, buscar aliviar o abandono e, nesse sentido, buscar novos arranjos junto a órgãos públicos e particulares para a redefinição de vínculos tão pobres nas instituições.

Com o avanço dos anos, deparamo-nos com uma série de perdas significativas: o surgimento das doenças, a viuvez, a morte de amigos e parentes, a ausência de papéis sociais valorizados, o isolamento crescente, as dificuldades financeiras decorrentes da aposentadoria. Tudo isso afeta a auto-estima, culminando, na maioria das vezes, em diferentes formas de violência.

O desejo de descansar, então, pode estar sendo adotado como uma estratégia de contração, refletindo a crença de que a redução do número de desejos e exclusão de atividades não mais recompensadoras contribui para, ao menos, produzir um suporte para continuar vivo. Pode ainda estar vivenciando, com este afastamento, a idéia generalizada, e expressa por muitos dos idosos, de que o processo de envelhecimento é, primariamente, perda e negação. Conseqüentemente, nada mais resta a fazer. A maioria não vê outra 
alternativa nessa situação de perdas quase absolutas que não aguardar a morte. No sentido figurativo, estão realmente mortos por antecipação.

A sociedade, como um todo, deve ser questionada a respeito da qualidade de vida que está oferecendo a essas pessoas. Que esforços que estão sendo feitos para modificar essa realidade? Como fazer para conter ou amenizar as crises cognitivas, afetivas e biológicas que chegam com a idade? Quais as mediações necessárias para que aconteça uma atenção mais generosa nas casas onde fazemos nossa prática de psicologia do desenvolvimento?

Cartazes, ao passarmos em frente a um muro, mostravam a seguinte frase pichada: "Velhice é o domingo da vida". Por que o domingo? Certamente, porque é o dia em que tudo está fechado, em que as oportunidades estão fechadas, a sociedade está fechada para isso. Ou será por que é o dia de descanso? Descanso de quê? Descanso da vida? Será que as pessoas precisam deixar de viver, deixar de acreditar em seus sonhos para descansar todos os dias de sua vida depois dos sessenta anos de idade? E ainda comentamos: se, ao menos, elas pudessem se despedir com certa dignidade, mesmo que fossem em casas que, de origem, não são as suas.

\section{Algumas Impressões dos Diferentes Relatórios}

As seguintes impressões destacaram-se nos relatórios dos grupos de alunos:

\subsection{Resistência}

A resistência dos idosos foi grande em relação ao nosso grupo (1) ${ }^{1}$. Eles foram convidados a escrever algo de suas vidas nas mãos desenhadas no papel. Dava a impressão que as coisas de suas vidas não mereciam mais consideração. Eram de pessoas que um dia viveram e construíram muitas coisas, pois as frases que ouvíamos eram: "Eu fiz tantas coisas em minha vida." Mas ficava por aí o diálogo. Mesmo quando insistíamos em fazer com que se expressassem, pouco ou nada de específico era resgatado. Ao solicitarmos a outros que falassem alguma coisa sobre algum idoso, o que eles sabiam era somente o nome, mas, muitos nem a isso chegavam.

\footnotetext{
${ }^{1}$ Foram constituídos seis grupos para o trabalho de campo da Disciplina Psicologia do Desenvolvimento III.
} 
Durante nosso trabalho, percebemos a falta de atenção da família, ou do que dela restara, principalmente do filho de um dos residentes. A este causa tristeza, desamparo e sensação de abandono, que não é demonstrado explicitamente, porém é evidente seu sofrimento quando refere que seu filho é muito ocupado e não tem tempo para visitá-lo. Está quase que diariamente à sua espera, o que lhe causa momentos de angústia com evidentes sinais de depressão.

\subsection{Falta de Ética ou Desrespeito}

O nosso grupo (2) preparou-se para ir ao asilo levando, balas, balões, um rádio com $C D s$ e sementes para a horta de seu Adolfo. Era um dia de sol. Chegamos alegremente e percebemos que os idosos estavam mais desinibidos. Penduramos os balões, e o dono da casa nos deixou bem à vontade, chamando os "velhinhos" somente pelo apelido e falando abertamente, na frente de todos os idosos, a história de cada um, incluindo suas doenças, o que consideramos completamente antiético. Depois de uma breve conversa, distribuímos as balas durante seu lanche da tarde, o qual ajudamos a servir.

Neste dia, assistimos ao senhor Ivalino gritando de dor e urinando no meio da sala. Vimos também os maus-tratos da funcionária do asilo, que o arrastou para dentro do quarto, onde somente trocou as suas calças, sem limpá-lo.

\subsection{Abandono}

Na chegada ao asilo o nosso grupo (3) deparou-se com o estado deplorável de Dona Geni. Ela estava sentada num sofá, com a pele do rosto queimada, irritada devido a uma secreção lacrimal e à falta de cuidados para com ela. Ao sairmos da casa, decidimos buscar ajuda para resolver o problema. Fomos até a Secretaria Municipal da Saúde, onde, após vários contatos, fomos informadas de que os médicos estavam impossibilitados de atendê-la devido à redução de horário e à falta de combustível. Logo após, fomos até os bombeiros, que se dispuseram a buscá-la e levá-la até o prontosocorro, mas havia necessidade de uma pessoa responsável para acompanhála. 


\subsection{Incredulidade}

O nosso grupo (4) surpreendeu-se ao ler na ficha que o senhor Honório tinha distúrbio mental. Era um dos poucos que participava de todas as atividades; desenhou casas e ruas, e tem total liberdade de passear sozinho. É também o único que mora num espaço separado da casa, reservado somente para ele. Manteve boas relações conosco, sendo julgado como muito esperto, divertido e prestativo. Tem total autonomia física, mas é olhado como alguém que está com disfunção cognitiva. Esta é outra lição a ser tomada: é preciso uma melhor avaliação e abordagem diante da diminuição severa da identidade daqueles que aí estão, deixando-os iguais àqueles que se encontram em pior estado.

Enquanto uma senhora contava coisas de sua vida para escrevermos nas mãos desenhadas no papel, ouvíamos que sempre fora uma pessoa bondosa, justa e que nunca se separa de sua fé, de seu Deus. Ela estava lendo a Bíblia e, no momento em que estávamos nos despedindo, ela disse: "Rezem por mim. Rezem para que descanse logo." A espiritualidade estava sendo invocada como esperança e refúgio, servia como consolo para que aquele pesadelo logo acabasse. Para alguém que viveu sua vida em plenitude cristã, estar em uma cadeira de rodas, esperando a morte chegar e pedindo diariamente para que não tarde, a espiritualidade ganha uma dupla função: uma forma de aproximar-se do Criador, da recompensa por ele prometida e uma forma de suportar os últimos dias, não como um sentido de vida, mas como um alívio por encontrar-se inútil.

\subsection{Impotência}

A revolta de nosso grupo (5) é sermos impotentes.

Queriam nos agradecer tocando-nos, olhando profundamente nos nossos olhos. Na ala dos doentes, encontramos uma paciente, S., numa crise de choro, gritos e lamentações, pedindo pela família, pelos filhos, pelo padre, dizendo que ela não passaria do meio-dia, que iria morrer; assim, repetidamente, chorava e lamentava sua situação. Comunicamos à nossa supervisora o que estava ocorrendo, e ela foi até a paciente; tentou conversar, acalmá-la. Também comunicamos o fato à responsável pelo asilo, que foi ver o que acontecia. A paciente também implorava para se deitar, porém o procedimento adotado foi o de deixá-la sentada na cadeira, pois, se a 
deitássemos, ela adormeceria e passaria o dia sem comer. Esse fato afetou intimamente o grupo, ficando retido, em nossas mentes e corações o desespero da paciente e a nossa impotência diante de uma situação arrasadora para ela.

Sentimo-nos inseguras, impotentes frente a tal realidade, e, ao mesmo tempo, revoltadas e deprimidas por termos de nos "conformar" com essa realidade em função do que se pode fazer em relação a isso. Também ficamos chocadas frente às limitações físicas, mas ao mesmo tempo, empolgadas com a missão de realizar um trabalho que trouxesse resultados positivos e gratificações pessoais tanto para nós quanto para eles.

O relacionamento entre as asiladas é bom, com exceção de algumas idosas. "[... ] eu não vou sentar na sala com aquela bruxa, ela é má, ela tem fogo nos olhos [ ...]" depoimento de uma interna ao se referir a outra. Quando a convidamos para que se sentasse junto conosco e com as outras, ela não quis, mas, no geral, elas se divertem juntas, rindo uma das características da outra, sem zangar-se entre elas: "[ ... ] que boba, ela ri de qualquer coisa, nunca vi coisa igual”, referindo-se às gargalhadas de outra. “[... ] Essa aí só pede pela boneca, chega alguém e ela começa a pedir pela boneca."

\subsection{Fragilidades}

Surgiam percepções difíceis de serem aceitas para nosso grupo(6), em face das deficiências das residentes: Doralina não liga nada com nada. Apresenta-se muito ansiosa, a onde íamos, ela estava sempre atrás dizendo: "E agora? Agora o que eu faço?" Estava sempre inquieta. Quando sua filha vai visitá-la, vai para o quarto se esconder. Só conversa com sua neta.

Maria aos 92 anos, não se levanta muito da cama. Quando vamos visitá-la no quarto, está sempre deitada com a coberta no rosto. Não sabemos bem o porquê, mas, na conversa, ela contou que quando era criança, apanhava muito de seu pai. Um dia resolvemos elogiá-la dizendo-lhe para tirar a coberta do rosto porque ela era muito bonita e ela falou: "É, eu sou bonita mesmo? Será que os moços ainda me querem?"

Malvina apresenta fragilidade na fala e incoerência nos pensamentos. Sempre carrega um saquinho com alguns objetos dentro, mas não os mostra para ninguém. Não usa o crachá que fizemos, pois também o guardou no seu saquinho. Demonstra muito afeto e simpatia. 
Maria, cega, parece estar muito distante da vida. Quando conversarmos com ela diz que está perdida e no escuro e pede: "Minha filha, ligue a luz para mim!"

5 Concluindo: para além das categorias acadêmicas

Ao final do semestre, com base nos relatórios e na reunião de avaliação, pode-se depreender o que segue.

Os olhares das universitárias estão carregados de dor, de solidariedade, de revolta e, infelizmente, de impotência diante de cenas do sofrimento dado ao destino de um grupo de casas e de seus residentes, em sua maioria, sem apoio público, como se a velhice tardia e sem vínculos fosse apenas uma questão particular. O relatório faz ver que as alunas não estavam dispostas a assumir passivamente a realidade apresentada, suas falas revelam que urgia um encaminhamento mais responsável que a prática de uma psicologia de abordagem meramente cognitiva, solicitando somar aos aprendizados oferecidos outros relativos a procedimentos a uma moralidade social reconstrutiva. A sensibilidade do cuidado ultrapassava as solicitações acadêmicas, entretanto, ficavam tão pequenos seus gestos delicados que podiam ser comparados aos versos que citaram para dizer sua frágil solidariedade.

Os homens que se achavam no café
Tiraram o chapéu maquinalmente
Saudavam o morto, distraídos.
Estavam todos voltados para a vida,
Absortos na vida,
Confiantes da vida.

As falas das acadêmicas eram eloqüentes e demonstravam sempre o desejo de aprender o caminho da solidariedade através de uma gestão social mais organizada, tendo nos seus horizontes mais igualdade. As suas narrativas revelam a insatisfação em apenas avaliar e compreender o fenômeno asilar.

As alunas percebiam o quanto o atendimento negava a dignidade. Sentiam-se solitárias, como se a realidade aí exposta devesse ser assim e se apenas a elas fosse conferido o dever de fazer alguma coisa. Parecia que $o$ destino humano era esse e que apenas algumas considerações emergentes de apoio pessoal poderiam substituir a grande falta social. O esforço acadêmico 
também se associava a esta falta, que, possivelmente, redundaria numa lição do descompromisso.

A angústia e a decepção diante da realidade asilar, sem outros arranjos, eram resultado de uma gestão social da velhice tardia e dependente que se revelava inaceitável. A ingenuidade das alunas e sua perplexidade não podiam ser entendidas como normais, mas como expressão da inconformidade, revelando-se a irresponsabilidade da sociedade civil e dos órgãos públicos em promover arranjos sociais inovadores para com aqueles que possuíam carências em seus vínculos e em sua competência pessoal. Em suas palavras, revela-se um pedido para aprendizados de intervenções para provocação de comportamentos mais solidários. Cabe aqui uma análise austera em torno do silêncio da academia em face da violência em torno dos mais velhos, fazendo urgir um aprendizado de intervenções mais objetivas.

Vendo o que viam, tanto na degradação humana como em sua desconsideração, as alunas ficavam decepcionadas por não haver instrumentos de aperfeiçoamento social capaz de dar melhor destino à gestão social que se punha como omissa e excludente. A percepção juvenil não entendia com clareza o universo que se apresentava contundente.

Revela-se no discurso da alunas, juntamente com a impotência, uma denúncia que solicita um encaminhamento ético às questões da velhice tardia. Solicitam, na prática, aquilo que, teoricamente, haviam estudado em leituras com o professor: $\mathrm{O}$ envelhecimento pode ser representado como um universo de espaços vazios a serem organizados pela renovação ética e pelas políticas do conhecimento. Os reducionismos conceituais sobre as faixas etárias constituem-se em regimes disciplinares perversos e, em razão disso, alguns sinais de envelhecimento conduzem os sujeitos a se afastarem completamente do desenvolvimento.

O esforço das alunas pode ser avaliado como aproximações de ternura com exercícios de dinâmicas diferentes. O café da tarde servido na mesa para os residentes, o café na cama para os doentes, os desenhos provocados com carinho e cujos resultados revelavam sentimentos de perplexidade e simplicidade quase absoluta, as músicas e as danças, as histórias e os silêncios respeitosos, os olhares de compaixão e solidariedade, o baile do dia 8 de dezembro, reunindo todas as casas, foram caminhos de encontro. Porém, de qualquer ângulo pelo qual se olhe, representam intervenções minimizadoras, mas não resolutivas do abandono social. 
Essas questões foram elucidadas nos relatórios dos diversos grupos de alunas nos itens relativos aos títulos sobre as casas e seus moradores, as dores, a impotência e a oferta de pequenos consolos. Foram organizados seis grupos cada qual com a responsabilidade de apoiar um asilo e propor atividades com dinâmicas de grupo, jogos, café conjunto, visitas com conversas individuais e outras. As narrativas têm a pretensão de buscar, também pela academia, saídas participadas e ou proposições objetivas sobre intervenções sociais mais vigorosas.

A reinterpretação dos costumes em torno da velhice, em situação de abandono não foi suficientemente aprofundada. Pareceu que a questão foi tratada do ponto de vista explicativo, não reconstrutivo. Antes de mais nada, a presença das alunas serviu para verem, apoiarem e analisarem, mas o compromisso ético, no sentido de alterar os significados e os comportamentos em torno dos clamores, não foi cotejado suficientemente. Os caminhos da ética e da reconstrução de costumes não foram vistos como algo factível, uma vez que a universidade, dentro do paradigma das ciências está preocupada em construir conhecimentos, deixando as questões da ética social e sua transformação para outras instâncias sociais, políticas ou religiosas. $\mathrm{O}$ estranhamento do cotidiano, as implicações éticas e seus caminhos renovadores, os debates e embates sociais para a renovação dos estoques na gestão social das diferenças graves parecem ainda distantes das lides escolares.

No presente estudo, tanto para os professores envolvidos como para as alunas, havia a preocupação de buscar uma abordagem mais concreta de conhecer o fenômeno do abandono social. Pretendíamos apenas que os exercícios fossem nos concedendo melhor clareza sobre as causas que levam os mais velhos às residências asilares e suas conseqüências sobre eles. Apenas tínhamos a preocupação de que o fenômeno pudesse ser conhecido e de que algo pudesse ser feito, na dimensão estritamente acadêmica. A honestidade ética parecia nos faltar, uma vez que não aprendemos a ver todas as direções de um impacto, ou, mesmo, de qualquer outra realidade que, muitas vezes, pode ser constrangedora, mas por nos ser familiar torna-se suportável, ou, mesmo, imperceptível como problema, porque parte da trama da organização social. As nossas explicações e nossas tradições muitas vezes ocultam a verdadeira dimensão de um fato, reforçando-se costumes e explicações como se estas fossem suficientes. 
Os esforços realizados pelas alunas foram importantes dentro do projeto previamente estabelecido. Os relatórios denunciaram, porém, que o aprendizado foi insubsistente porque não apontou, suficientemente, para propostas e intervenções juntamente com a Secretaria Municipal de Saúde e outras parcerias que pudessem indicar melhores caminhos para os chocantes acontecimentos observados.

Uma análise crítica das narrativas revela que o impacto sofrido e as ações solicitadas tratavam de forma superficial das questões do sofrimento. As alunas sentiam-se frágeis e solitárias em face das dores que se lhes apresentavam. A realidade do atendimento foi acertada quanto ao projeto existente, mas a realidade social subjacente ao atendimento não condiz com aquilo que é humanamente justo. Num dos relatórios é narrado um fato que faz entrever a ponta do problema.

Indignação! foi o nosso sentimento em relação ao descaso dado a uma senhora idosa. Nos deparamos com sua imagem desvalida. Sentada no sofá, bengala ao lado, o seu rosto parecia arder em chamas. As lágrimas corriam-lhe por razão de uma infecção nos olhos. Estas lhe causavam um prurido o qual ela aliviava passando uma blusa de lã. Era uma tarde de verão com aproximadamente trinta graus. Perguntamos aos cuidadores sobre o que haviam feito: nada. Desculparam-se dizendo que: 'Os familiares foram avisados e estamos esperando que alguém apareça.' Dois dias de sofrimento, de descaso, a dor do abandono expressa em seu rosto envelhecido, e, principalmente, triste! Buscamos várias possibilidades para que a senhora fosse medicada e, então, nos deparamos com um monstro chamado burocracia.

De porta em porta andaram as alunas até que, "[ ... ] finalmente, o problema foi desta vez solucionado pela boa ação de uma pessoa humilde." Mas elas se interrogam: "E amanhã? Quem vai socorrer os velhos dessas instituições?"

As denúncias poderiam ter sido feitas por todas as alunas, mudandose apenas o paciente e as dores. Não existe uma rede social de apoio a 
idosos com vínculos e ou saúde fragilizados. Não existe uma política pública que dê suporte aos velhos em abandono. As casas de atendimento não estão legalizadas em sua maioria, nem apoiadas. As exigências legais existem e são cobradas, mas o apoio do Estado é mínimo ou não existe. Aí reside a maior preocupação: o aprendizado das alunas se torna restrito, uma vez que não concorrem formas consistentes de apoio, o que levaria a que aprendessem sobre caminhos e soluções diante desta espécie de síndrome de insuficiência familiar.

A violência do poder público, em razão da omissão, é grave. As alunas, então, ficam avaliando burocraticamente a trajetória e a situação biopsicossocial dos idosos, pouco aprendendo do que fazer com idosos em situação de risco social.

À universidade cabe aperfeiçoar as interpretações culturais e sistematizar conhecimentos, sendo honesta com os fatos descritos, e ao Estado cabe a melhoria das vias políticas para uma gestão social mais justa. A academia lava suas mãos dizendo que faz o que deve ser feito, não se comprometendo com as lutas políticas. Incitamos, assim, os mais jovens a estarem conformados, pois a função da universidade é pesquisar para compreender os fenômenos, ensinar o que é apreendido pela pesquisa e alimentá-la pela presença na comunidade. Mas esta não oferece suficientes subsídios na construção de costumes de abrigo generoso e a universidade satisfaz-se com apenas esclarecer.

O clamor das alunas e dos residentes do projeto da disciplina Psicologia do Desenvolvimento III invoca a proposição de parcerias para um processo de aprendizado comprometido. Uma análise crítica da legislação, encaminhamentos políticos, discussões e saídas com a promotoria, com as secretarias municipais, com a coordenadoria de ensino, órgãos não governamentais poderiam concorrer para um aprendizado da responsabilidade social. Assim, as alunas não receberiam apenas esclarecimentos científicos e sem a competência da ética social no seu processo de aprendizagem. 


\title{
GERONTOLOGICAL EDUCATION: a critical narration from the reports of a learning practice in old assistant houses
}

\begin{abstract}
The text consists in a critical narration of a learning practice in old assistant houses, in Development Psychology III subject, produced by the psychology's students from the University of Passo Fundo, in the year of 2000. The main idea is the critique on academic learning which takes place without worrying about developing the meaning of ethical responsibilities facing the gerontology knowledge. The narration intends to make evident the importance of a learning which approximates the scientific sense and the ethical development of the students. The intention of the analysis is to improve the academic learning, that has as a rule, the rationality looking for the problems, while this is methodologically correct. The qualitative analysis of the students effort was, by seeing the elderly more closely, and staying with them for a long time, to try to develop a university profile linked to morality and, as a result, to get correct social events. To close, the students revealed perplexity and impotence facing a social picture of suffer, and about the practical learning, they get almost nothing. It became evident the need of more convenient social interventions in the old assistant houses.

Keywords: Formation. Ethics and Old Age.
\end{abstract}

\section{REFERÊNCIA}

HABERMAS, Jürgen. Teoria de la acción comunicativa I e II. Madrid: Taurus, 1992. 